\title{
Review
}

Eva Zimmermann (2017). Morphological length and prosodically defective morphemes. (Oxford Studies in Phonology and Phonetics.) Oxford: Oxford University Press. Pp. xii +350 .

\section{Shanti Ulfsbjorninn}

University College London

\section{Overview}

In this first volume of the Oxford Studies in Phonology and Phonetics series, Eva Zimmermann offers a monograph on the phenomenon she calls MORPHOLOGical Length-Manipulation (MLM). She attempts to provide a full theoretical account of the typology of the phenomenon, while maintaining the hypothesis that all morphological processes are root-additive. Introducing her own framework, Prosodically Defective Morphemes (PDM), she proposes that all non-templatic non-concatenative processes (even subtraction) can be analysed by the interaction between prosodically defective morphemes and the constraints that regulate their integration. Zimmermann shows that MLM shares distributional characteristics with affixation (including infixation), something which is predicted by PDM if MLM is a consequence of affixation, but which competing accounts must treat as a coincidence.

In this review, I will present the basics of Zimmermann's framework, and focus on its two main claims: (i) MLM operates by affixation, and (ii) subtractive processes can be caused by addition of morphemes.

\section{Morphological Length-Manipulation}

MLM is any case where segmental quantity (lengthening, shortening, epenthesis and deletion) is affected in response to morphosyntactic information.

Two of Zimmermann's examples of MLM phenomena are given in (1), the additive case of Gidabal (p. 4), and the subtractive pattern of Hausa (p. 128). In Gidabal the imperative is formed by lengthening the final vowel of the base (1a), and in Hausa proper nouns are formed by shortening the final long vowel of the base (1b).

(1) Additive and subtractive morphology

a. Additive (Gidabal)
Base
gida 'tell' gida:
ma 'put' ma:
jaga 'fix' jaga:

$\begin{array}{ll}\text { b. Subtractive (Hausa) } & \\ \text { Base } & \text { Proper noun } \\ \text { marka: 'rainy season' } & \text { marka } \\ \text { baiko: 'stranger' } & \text { barko } \\ \text { baki: 'black' } & \text { baki }\end{array}$




\section{Review}

In languages such as Wolof, certain affixes have the lexically specific property of causing length changes to segments of the base (pp. 6,97).

(2) MLM in Wolof
a. Additive affix
lem i lem:i
fold REvERsive 'unfold'
b. Subtractive affix
son: al sonal
be tired causative 'tire'

Zimmermann sets out not just to explain what is attested, but also to exclude what is not attested. Her aim is not merely to produce a descriptive typology of MLM, but to reconcile its non-concatenative properties with a purely Item-andArrangement morphology (cf. Bonet 2008), the approach most compatible with a Distributed Morphology linguistic architecture. This shows the scale of the author's ambition, because Item-and-Process type morphology was specifically developed to account for the 'apparently obvious' fact that not all morphology involves the addition of affixal material (Anderson 1992, Aronoff 1994). Zimmermann's insistence that root-additive morphology is all that is needed bears a similarity to Marantz's (1982: 436) core observation that reduplication involves a 'normal affixation process'. For Marantz, a segmentally empty affix is concatenated with a base to produce reduplication, while in Zimmermann's account a segmentally empty mora can be inserted to trigger lengthening of the base. ${ }^{1}$

The conceptual base of defective morphemes had precursors, but many innovations were required to account for MLM effects, which are more complicated than reduplication. Subtractive morphology in particular appears very process-like, and not at all affix-like. Moreover, MLM can be both additive and subtractive in the same language, and multiple types of MLM can operate on the same morpheme, and accompany reduplication and other segmental changes (particularly challenging in a fully parallel framework). The types of pattern that have to be accommodated can be complicated, as in Aymara (pp. 149-170) or Upriver Halkomelem, illustrated in (3) (p. 214).

(3) Multiple MLM in Upriver Halkomelem

\begin{tabular}{|c|c|c|c|}
\hline & Non-cont & inuative & Continuative \\
\hline a. Stress shift & ts'eté:m & 'crawl' & ts'ćtəm \\
\hline b. Reduplication & mát’əs & 'point' & mámət'əs \\
\hline c. Lengthening & P'ixət & 'scrape' & Píizət \\
\hline & hílt & 'roll something over' & hílt \\
\hline d. Epenthesis & wáq’w & 'drown' & háwq’w \\
\hline
\end{tabular}

As we see in (3a), if the base has non-initial stress, the continuative is formed by stress shift. If the base has initial stress, it is formed by reduplication (3b), and if it begins with a glottal consonant, it is formed by lengthening of the initial vowel (c). Finally, if the stressed vowel of the base is a schwa, it is formed by epenthetic insertion of [hə], accompanied by deletion of the base schwa (d).

For MLM phenomena such as those found in Upriver Halkomelem Zimmermann proposes a simple and elegant model, in which all MLM is root-additive. In this heavily representational solution, MLM is always caused by the interplay of the affixation of a 'prosodically defective' morpheme and the grammatical constraints

1 However, there is another difference: reduplication seems to need to operate by copying, while the MLM seems to operate by spreading. 
that regulate its integration. The space of possibilities is sketched out in a fully parallel Coloured Containment version of Optimality Theory (cf. Prince \& Smolensky 1993, van Oostendorp 2006, Revithiadou 2007). Consequently, Zimmermann's framework allows each instance of MLM to receive something approaching a unified analysis, without recourse to morpheme-specific constraints (e.g. Pater \& Coetzee 2005, Pater 2009), transderivational antifaithfulness (Alderete 2001) or cophonologies (Orgun 1996, Inkelas et al. 1997).

\section{Representations at the forefront}

3.1 Configurations and constraints. Zimmermann's book lays the explanation for the MLM phenomenon firmly at the door of representation: extraordinary effects (MLM) are caused by ordinary processes (addition) operating on extraordinary things (defective morphemes). What makes this approach so insightful is that the configurational possibilities of phonological objects are predicted by autosegmental first principles.

In addition to the well-known one-to-one, one-to-many and many-to-one configurations, there are also three other contrastive arrangements of phonological objects, which be referred to as involving fixed, floating and empty nodes respectively. Following Zimmermann's conventions, the representations in (4b) and (c) can be grouped together as 'defective'.

$$
\text { a. Fixed b. Floating }
$$

c. Empty

mora

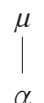

$\mu$

segment

$\alpha$

For PDM, however, proposing defective morphemes requires some rethinking of the classical assumptions behind the prosodic hierarchy, something anticipated in Kiparsky's (1991) catalexis-based solution. The PDM framework shows particularly clearly that the prosodic hierarchy is not a series of projections sensu stricto, as they are in syntax, where (5a) is impossible. Prosodic constituents are independent phonological objects that are related to each other via association lines (not by projection), as in (5b), and regulated by weak layering.

(5)

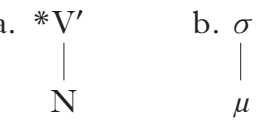

Once the prosodic hierarchy is seen as a collection of independent phonological objects, each on their own tier, mismatches between the tiers are actually predicted. So, although the defective representations shown in (4b) and (c) may look strange, or overly rich, to exclude them would actually require extra stipulations or conditions. In Zimmermann's terms, the defective structures are predicted by richness of the base, and should not be arbitrarily excluded, since they predict phonological surface effects (p. 40).

By definition, defective morphemes are inputs whose nodes fail to dominate or be dominated by nodes that they would ordinarily dominate or be dominated by. Consequently, in PDM constraints regulate the association of each prosodic node on tier $n$ with nodes on both tiers $n+1$ and $n-1$. One constraint-type (DD) ensures that a node is dominated by a node on tier $n+1$ and another (Do) ensures that a 


\section{Review}

node dominates a node on tier $n-1$ (p. 42). These are collectively known as PARSING CONSTRAints; examples are $\mu$-DD- $\sigma$ and $\mu$-Do-S $(\mathrm{S}=$ segment $)$. Full integration occurs in outputs where the relevant Do and DD are unviolated, while any violation signals the presence of a defective node in the output. The basic configurations for full and defective integration are shown in (6). (Phonological objects that are shaded are phonetically invisible.)

(6) Basic configurations in PDM

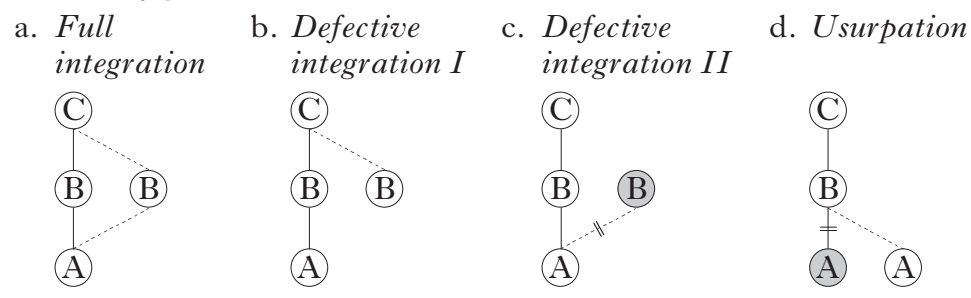

Zimmermann's central claim is that prosodically defective morphemes can result in MLM. Therefore, the contrast between underlyingly incomplete and complete prosodic structures does not become neutralised in the output (p. 43). The state of affairs where underlying states are preserved throughout the derivation is well modelled by the principle of containment: 'every element of the phonological input representation is contained in the output' (cf. Prince \& Smolensky 1993). In containment theory there is no deletion of phonological objects from the input, though these can be left unpronounced in the output, as indicated by shading in (6).

Zimmermann's theory of containment goes even further, demanding that the whole of the input must be reconstructable from the output at any time: not just the phonological objects, but also the relations between those objects: the association lines. Following Trommer (2011) and Trommer \& Zimmermann (2014), association lines can be marked as being invisible to the phonetics, resulting in the stray erasure of any phonological objects they dominate, as shown in (7) (p. 45$).^{2}$

(7) Types of association relations

$\begin{array}{cccc}\text { a. Underlying, } \\ \begin{array}{c}\text { phonetically } \\ \text { interpreted }\end{array} & \begin{array}{c}\text { Underlying, c. Epenthetic, } \\ \text { phonetically } \\ \text { notinterpreted }\end{array} & \begin{array}{c}\text { phonetically } \\ \text { interpreted }\end{array} & \begin{array}{c}\text { Epenthetic, } \\ \text { phonetically } \\ \text { not interpreted }\end{array} \\ \text { A } & = & \text { A } & \text { A }\end{array}$

This distinction is carried over into constraints that specifically penalise epenthetic association lines. The principles of visibility follow naturally, ensuring that (a) every association line linking a phonetically invisible object to a lower object is phonetically invisible, and (b) every object is phonetically invisible iff it is not associated to a higher prosodic node by a phonetically visible association line (p. 45).

2 This is similar to the distinction between projection and pronunciation in Goldrick's (2000) Turbidity Theory and developments of this framework (van Oostendorp 2006, Revithiadou 2007). In the former the distinction is an abstract relation, and in the latter visibility to the phonetics. 
3.2 Morphological colour. Zimmermann's containment theory is based on the theory of morphological colour, which claims that every morpheme has an underlying colour (van Oostendorp 2006, Revithiadou 2007, Trommer 2011). In what follows, morphological colour is shown as a subscript symbol. Each morpheme has a unique colour, therefore each subscript is also unique. Morphological colour cannot be changed throughout the derivation, so the morphological structure of words is always reconstructable at any point in the derivation. Epenthetic objects do not have a morphological colour. Consequently, colour is also the mechanism by which epenthesis is regulated, with constraints such as CoL!S: 'assign a violation mark for every segment not licensed by morphological colour' (p. 51).

3.3 Demonstration of PDM. Before turning to a critical discussion of the book's two main contributions, I will demonstrate how the PDM framework operates for Yine, which has a process of morphologically conditioned vowel deletion. Zimmermann explains this using a mechanism she terms 'mora usurpation'. Some affixes trigger the deletion of a morpheme's preceding vowel (pp. 86-96). These affixes are said to be 'subtractive', and are underlined.

(8) One leftward vowel deletion from subtractive affix

a. Deletion of a stem vowel pawata-maka pawatmaka 'I would have made a fire' neta-lu netlu 'I see him'

b. Deletion of a suffix vowel meji-wa-lu mejiwlu 'celebration' wujlaka-na- $\underline{\text { lu }}$ wujlakanru 'we hit him'

The process does not appear to be phonologically or syntactically conditioned; subtractive affixes form an arbitrary set, which is not identified by any morphosyntactic property. Furthermore, subtractive affixes can be homophonous with nonsubtractive affixes: / hata-nu/ $\rightarrow$ [hatnu] 'light, shining' vs. /heta-nu/ $\rightarrow$ [hetanu] 'going to see' (p. 87).

To account for the data in PDM, Zimmermann proposes the following analysis, which relies chiefly on three constraints: $\mathrm{V}<\mathrm{DD}_{\mathrm{p}}^{\mathrm{m}}<\mu$, a parsing constraint that regulates association between syllables and moras, ${ }^{*} \sigma$-CoL! $\mu$, which penalises syllable nodes that dominate colourless (epenthetic segments), and ${ }^{*}{ }^{\mu}{ }_{v}$, which penalises moras associated to multiple vowels (p. 89).

The representational component of PDM is the assumption that subtractive morphemes are prosodically defective, in the sense that they do not have underlying moras. For the input /neta-lu/ in (8a), the output in (9), [ne.t ${ }^{2} .1 u$ ], is selected as optimal because the subtractive affix does not have its own mora. ${ }^{3}$

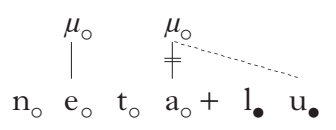

Consequently, it could either acquire a mora epenthetically or share an underlying base mora. The fact that both of these strategies are suboptimal is explained by the high-ranked constraints against a vowel sharing two moras: ${ }^{*} \mathrm{v}^{\mu} \mathrm{V}$ and ${ }^{*} \sigma-\mathrm{CoL} ! \mu$. As

3 A fully predictable schwa, shown as a superscript, marks the site of each vowel deletion. 


\section{Review}

a result, the defective vowel of the subtractive affix must associate to a coloured mora of the base (which is not allowed to remain phonetically linked to its underlying segment, due to ${ }^{*} \mathrm{v}_{\mathrm{v}}{ }_{\mathrm{v}}$ ). Accordingly, subtractive affixes usurp the moras from segments of the base, resulting in their phonetic non-interpretation.

\section{Critical discussion of PDM}

4.1 MLM has the same distribution as infixation. The central aim of Zimmermann's book is to show that MLM phenomena result from the 'ordinary' affixation of prosodically defective morphemes. Treating all instances of MLM as affixation leads to some impressive typological conclusions, as can be seen in Table I. ${ }^{4}$

\begin{tabular}{c|r|r|c|c|c|}
\cline { 3 - 6 } \multicolumn{1}{c|}{} & \multicolumn{4}{c|}{ Affected base edge } \\
\cline { 2 - 6 } \multicolumn{1}{c|}{} & left & right & ambiguous/both & total \\
\cline { 2 - 6 } (a) & 12 & 22 & 4 & 38 \\
(b) & Addition & 3 & 19 & 2 & 24 \\
\cline { 2 - 6 } & Additive affixation & 3 & 18 & 3 & 24 \\
& Subtraction & - & 11 & 2 & 13 \\
\hline
\end{tabular}

Table I

Right $v s$. left edge of the base: (a) additive MLM; (b) subtractive MLM.

Suffixation is a far more common affixal strategy than prefixation, and as a result MLM is strongly biased to the right edge. In stark contrast, the competing approaches (summarised in Chapter 7) must conclude that MLM's preference for the right edge is a result of chance (p. 250).

The specifics of what positions in a base can be targeted by MLM phenomena is equally striking. In some original and highly effective diagrams, Zimmermann schematically lays out the positions of the base that are affected by MLM in 100 languages. These come from 33 language 'stocks', covering seven continentsized 'macro-areas' (p. 241). Compellingly, no segment further inside its base than its first or last vowel is ever affected by subtractive MLM (p. 253). For additive phenomena, if the MLM affix joins from the left, no additive effect is seen further right than the first coda of the base, whereas, if the MLM affix comes from the right, no position further left than the penultimate vowel of the base is targeted that is. In the 'vast majority of cases', additive MLM affects the first or last vowel of the base (p. 250).

Zimmermann rejects 'phonological dislocation' (Prince \& Smolensky 1993, Halle 2001), where phonological optimisation can in principle involve morphological changes in any part of the base (p. 68). She predicts that all MLM is

4 The fact that subtractive MLM is less often attested than additive MLM $(n=37$ vs. $n=62)$ reflects the relative markedness of the phenomenon. Zimmermann states that the subtractive pattern is more 'abstract' and harder to learn (p. 245). 
affixal, so the question becomes one of how to analyse the cases where MLM effects occur within the base. As we have seen, MLM cannot intrude very far into the base, but it is not restricted to segments and positions at its very edge. As Zimmermann notes, it is particularly interesting that the contexts for MLM are strictly parallel to the landing sites for infixation ('morphological pivot affixation'; Yu 2007) in (10). This is in fact predicted if MLM is thought to proceed like infixation and affixation. This is confirmation of a major prediction of the PDM model.

(10) Possible pivots for segmental affixes (Yu 2007)
a. Initial pivot
b. Final pivot
first consonant/onset
final vowel/nucleus
first vowel/nucleus
final syllable
c. Prominence pivot stressed syllable stressed vowel/ nucleus

Zimmermann attempts to provide her own Coloured Containment reanalysis of Yu's pivot points, but, unfortunately, the mechanism she introduces, the COLOUR INDEX (p. 74), lacks independent motivation. The colour index is an abstract object that has no equivalent either in the morphosyntax or the phonetic interpretation. Confusingly, PDM claims that the colour index contains 'purely morphological information', but it exists only at a specific tier of the phonology, and 'functions as a placeholder' for a phonological object. In (11) we see the colour index represented as a solitary black dot. It is located on the same tier as the mora, so the colour index functions essentially as a 'placeholder' on that mora tier.

\section{Colour index on the moraic tier \\ $\mu_{\bullet} \bullet$}

Though the colour index has no phonetic interpretation of its own, it is claimed to have indirect effects. In order to eliminate colour indexes (presumably by analogy with the removal of uninterpretable features in syntax; Chomsky 1995), the operation in (12) is introduced.

(12) Index fusion

Every empty colour index $。$ must fuse with an element on the same tier:

$\mathrm{X}_{\bullet}+{ }_{\circ} \rightarrow \mathrm{X}_{\circ}$

The introduction of colour indexes in Zimmermann's Coloured Containment theory allows GEN to construct outputs with morphological colours in the base, as in (13).

(13) Exponent order: $\mathrm{M}_{\circ} \gg \mathrm{M}_{\bullet}$

a. input

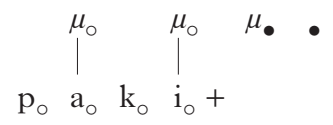

b. possible output

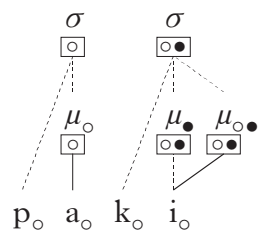

c. impossible output

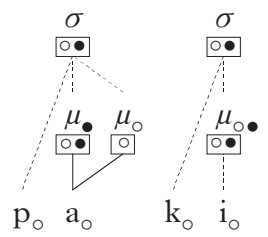




\section{Review}

The formal application of index fusion is elegant and intelligent, which is characteristic of the whole of the book, but the mechanism employed suffers from arbitrariness. Both the colour index and the operation of index fusion are argued to be 'purely empirically motivated' (p. 75), but in fact they seem to provide an arbitrary explanation for the observed empirical fact that the distribution of MLM is like that of infixation. Various questions arise with respect to colour indexes and index fusion: why can morphemes contain only one colour index?; why not two or three?; why can they not be preceded and followed by a colour index on the same tier? The stipulation that there can only ever be one colour index gets the facts right, but does not follow from any formal principle or interface/learnability condition. From the formal perspective, colour indexes are like placeholders for phonological objects, which begs the question: why not have multiple 'placeholders', just like multiple phonological objects in the representation of a morpheme? From the interface and learnability perspectives, the MLM phenomena would be equally learnable if morphemes were to contain multiple colour indexes.

The problem with this aspect of the colour index is quite serious, because it undermines PDM's explanatory force in generating the typology. Although PDM allows non-concatenative morphology to be analysed as root affixation, it does not appear to replace Yu's (2007) pivots with anything more explanatory.

4.2 Subtraction through addition. The second major analytical contribution of Zimmermann's PDM framework is the audacious claim that even subtractive morphology is purely additive. This step is crucial to restricting morphology to a purely Item-and-Arrangement system. This is a wonderfully counterintuitive notion (foreshadowed in Trommer \& Zimmermann 2010, and adopted by D'Alessandro \& van Oostendorp 2016). Although the logic of the mechanism is intriguing, I think it is fair to say that its implementation in this book is somewhat underdeveloped. Before I present my criticisms, I give a simple example in (14).

$\begin{array}{lll}\text { Two verb forms in Canela Krahô } \\ \text { long } & \text { short } & \\ \text { a. ihkulan } & \text { ihkula } & \text { '(someone) kills it' } \\ \text { ton } & \text { to } & \text { '(someone) makes it' } \\ \text { ihkahiul } & \text { ihkahru } & \text { '(someone) whips it' } \\ \text { katol } & \text { kato } & \text { 'he arrives' } \\ \text { b. cupa } & \text { cupa } & \text { 'fear it' }\end{array}$

Verbs in Canela Krahô come in either 'long' or 'short' forms, roughly corresponding to 'non-finite' and 'finite' syntactic contexts (Popjes \& Popjes 1986). Certain 'long' forms are marked by the presence of a final consonant, which seems to delete in the 'short' contexts, as in (14a). Vowel-final forms show no alternations, as in (b).

The PDM analysis is a simple but representative example of how subtractive morphology works in this framework. The short forms are a consequence of the affixation of a prosodically defective mora to a base (p. 111). A number of constraints and candidates are involved in Zimmermann's analysis, but the real interest revolves around the choice between the candidates where the affixed mora has an additive effect, $\mathrm{k}_{\circ} \mathrm{a}_{\circ} \mathrm{t}_{\circ} \mathrm{o}_{\circ}:_{\bullet} 1=[\mathrm{kat}: \mathrm{l}]$ or $\mathrm{k}_{\circ} \mathrm{a}_{\circ} \mathrm{t}_{\circ} \mathrm{o}_{\circ} \mathrm{l}_{\circ}:_{\bullet}=\left[\mathrm{kat} \mathrm{l}_{\mathrm{l}}\right]$, and the optimal subtractive output, $\mathrm{k}_{\circ} \mathrm{a}_{\circ} \mathrm{t}_{\circ} \mathrm{o}_{\circ}<\mathrm{l}>_{\bullet}=[\mathrm{kat} \mathrm{\jmath}]$ 'he arrives'. 
In Zimmermann's framework, the reason for the prosodically defective mora causing segment deletion are the high-ranked constraints $\mu>$ Do $>V$ and * $\sigma$ Af. $\mu$. The former forces the affixal mora to link to a segment, while the latter simultaneously penalises the attachment of an affixal mora to a syllable node. The optimal candidate will therefore be one where the affixal mora links to a base segment and at the same time does not link to a syllable. This lack of attachment to a syllable in the optimal candidate results not only in the mora's phonetic invisibility, but also in the phonetic non-interpretation of any segments it dominates. This leads to the appearance of deletion, as shown in (15).

\section{(15) Subtraction by addition}

a. input

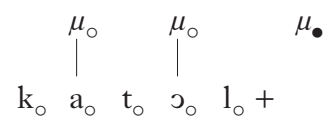

b. candidate excluded by affixal moraic node linking to a syllable node (* $\sigma \cdot$ Af. $\mu$ )

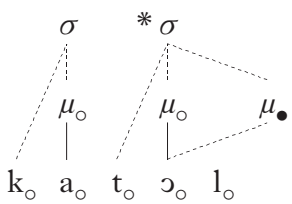

c. candidate with morphemic mora linked to segment and no higher node

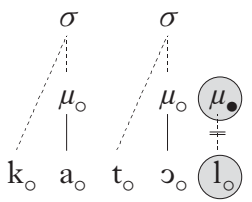

As far as I see, the mechanism or formal explanation behind the constraint family * $x$. Af. $y$ is underdeveloped, because [+Affix] is not a feature, and not part of the representation.

Zimmermann effectively suggests that there are base colours and affix colours. The phonology can directly access the distinction between base and affix, a distinction that is frequently found in phenomena discussed in the literature (p. 50). However, the motivation or reason for them having base $v s$. affix colours is not given. It is reasonable that each morpheme should have its own colour, because each is a unique object. So phenomena that show sensitivity to this uniqueness (conditions on integration) can be explained by each morpheme having its unique colour, an independent fact which supports this representational status. But the difference between bases and affixes cannot work in this way. What defines the classes of base and affix? If the answer is 'the colour', then the explanation is circular. Using colours like this amounts to no more than giving a description of the fact that phonological phenomena can recognise the difference between bases and affixes. The argument would work, however, if bases and affixes had different sets of colours because of some independent distinction; for instance, if they came from different lexicons, or if their representations were independently distinguished in some way, allowing them to form a natural class. 


\section{Review}

\section{Conclusion}

This is a book that leaves the reader far richer. The analysis of MLM is intelligent and elegant, but most of all architecturally important. The biggest contribution of the book, to my mind, is that it is a comprehensive demonstration that MLM phenomena operate by affixation. Reading Zimmermann's work and the impressive theoretical typology contained within it has left me in little doubt of this. The significance of this cannot be overstated, because non-concatenative morphology and subtractive morphology seemed to make it 'obvious' that morphology contained affixes and processes, or morpheme-specific constraints, or cophonologies, etc. I have also provided a critical overview of PDM and its implementation, challenging the mechanisms behind both major innovations, the first of which I find to be arbitrary and the second circular. However, that said, Zimmermann's book will make the task of anyone working on MLM effects in the future easier. They will be approaching the problem from the privilege of a well-established base-camp, higher up and with a clearer view from near the top of the mountain.

\section{REFERENCES}

Alderete, John D. (2001). Morphologically governed accent in Optimality Theory. New York: Routledge.

Anderson, Stephen R. (1992). A-morphous morphology. Cambridge: Cambridge University Press.

Aronoff, Mark (1994). Morphology by itself: stems and inflectional classes. Cambridge, Mass.: MIT Press.

Bonet, Eulàlia (2008). Item-and-Arrangement or Item-and-Process? Cuadernos de Lingüistica 15. 1-12.

Chomsky, Noam (1995). The minimalist program. Cambridge, Mass.: MIT Press.

D'Alessandro, Roberta \& Marc van Oostendorp (2016). Abruzzese metaphony and the $|\mathrm{A}|$ eater. In Francesc Torres-Tamarit, Kathrin Linke \& Marc van Oostendorp (eds.) Approaches to metaphony in the languages of Italy. Berlin \& Boston: De Gruyter Mouton. 349-368.

Goldrick, Matthew (2000). Turbid output representations and the unity of opacity. NELS 30. 231-245.

Halle, Morris (2001). Infixation versus onset metathesis in Tagalog, Chamorro, and Toba Batak. In Michael Kenstowicz (ed.) Ken Hale: a life in language. Cambridge, Mass.: MIT Press. 153-168.

Inkelas, Sharon, C. Orhan Orgun \& Cheryl Zoll (1997). The implications of lexical exceptions for the nature of grammar. In Iggy Roca (ed.) Derivations and constraints in phonology. Oxford: Clarendon. 393-418.

Ka, Omar (1994). Wolof phonology and morphology: a non-linear approach. Lanham, Md.: University Press of America.

Kiparsky, Paul (1991). Catalexis. Ms, Stanford University \& Wissenschaftskolleg zu Berlin.

Marantz, Alec (1982). Re reduplication. LI 13. 435-482.

Orgun, C. Orhan (1996). Sign-based morphology and phonology with special attention to Optimality Theory. $\mathrm{PhD}$ dissertation, University of California, Berkeley.

Oostendorp, Marc van (2006). A theory of morphosyntactic colours. Ms, Meertens Institute, Amsterdam. Available (November 2017) at http://egg.auf.net/06/docs/ Hdt $\% 20$ Oostendorp $\% 20$ coulours.pdf.

Pater, Joe (2009). Morpheme-specific phonology: constraint indexation and inconsistency resolution. In Steve Parker (ed.) Phonological argumentation: essays on evidence and motivation. London: Equinox. 123-154. 
Pater, Joe \& Andries Coetzee (2005). Lexically specific constraints: gradience, learnability, and perception. Proceedings of the 3rd Seoul International Conference on Phonology. Seoul: Phonology-Morphology Circle of Korea. 85-119.

Popjes, Jack \& Josephine Popjes (1986). Canela-Krahô. In Desmond C. Derbyshire \& Geoffrey K. Pullum (eds.) Handbook of Amazonian languages. Vol. 1. Berlin: Mouton de Gruyter. 128-199.

Prince, Alan \& Paul Smolensky (1993). Optimality Theory: constraint interaction in generative grammar. Ms, Rutgers University \& University of Colorado, Boulder. Published 2004, Malden, Mass. \& Oxford: Blackwell.

Revithiadou, Anthi (2007). Colored turbid accents and containment: a case study from lexical stress. In Sylvia Blaho, Patrik Bye \& Martin Krämer (eds.) Freedom of analysis? Berlin \& New York: Mouton de Gruyter. 149-173.

Trommer, Jochen (2011). Phonological sensitivity to morphological structure. In Marc van Oostendorp, Colin J. Ewen, Elizabeth Hume \& Keren Rice (eds.) The Blackwell companion to phonology. Malden, Mass.: Wiley-Blackwell. 2464-2489.

Trommer, Jochen \& Eva Zimmermann (2010). Generalized mora affixation. Paper presented at the 18th Manchester Phonology Meeting.

Trommer, Jochen \& Eva Zimmermann (2014). Generalised mora affixation and quantity-manipulating morphology. Phonology 31. 463-510.

$\mathrm{Yu}$, Alan C. L. (2007). A natural history of infixation. Oxford: Oxford University Press. 